\title{
Passive processing of visual and auditory stimuli in the young and elderly: a neuroimaging study
} Dan Joyce*1, Derek Tracy ${ }^{2}$, Thomas Dannhauser ${ }^{2}$ and Sukhwinder Shergill ${ }^{2}$

Address: ${ }^{1}$ The Institute of Psychiatry, De Crespigny Park, London, UK and ${ }^{2}$ The Institute of Psychiatry, London, UK

* Corresponding author

from International Society on Brain and Behaviour: 2nd International Congress on Brain and Behaviour

Thessaloniki, Greece. 17-20 November 2005

Published: 28 February 2006

Annals of General Psychiatry 2006, 5(SuppI I):S87 doi:10.1 186/1744-859X-5-SI-S87

\begin{abstract}
Background
There is surprisingly little literature on age-related effects in passive visual and auditory processing in humans. In this study, we use parameterised visual and auditory stimuli to investigate the relationship between a) visual frequency and graded visual cortical activations b) auditory word presentation frequency and graded auditory cortical activations in both young and elderly groups. We attempted to model the relationship between visual / auditory stimuli frequency and differential effects on cortical activation in both groups.
\end{abstract}

\section{Materials and methods}

Eleven young participants (mean age 36.9; right handed; no history of neurological or psychiatric disorder) and ten elderly participants (mean age 67.4; no history of neurological or psychiatric disorder) where scanned using an event-related fMRI paradigm. On each trial, participants either watched a checkerboard rotating at 2, 4 or $8 \mathrm{~Hz}$ or listened to nouns presented at 30,60 or 90 words-perminute. On some trials, the visual and auditory stimuli overlapped, enabling an exploration of multimodal cortical regions.

\section{Results}

Group level analysis (using SPM2, with activations reported surviving cluster-level correction at $\mathrm{p}<0.05)$ revealed that across the visual conditions (i.e. all frequencies) in the young group, Brodmann areas 18/19 - left inferior occipital gyrus and middle occipital gyrus - where activated. In the elderly group, Brodmann area 19 was again activated, but additionally BA 17 (right occipital lobe) and left frontal gyrus (BA 11) activation was also present.
In the auditory conditions, the young group showed activations in BAs 38 (right superior temporal gyrus) and 22 (left middle temporal gyrus). However, the elderly group showed more diffuse bilateral activations: on the left and right BAs 21/22 where present.

By parametrically modulating auditory and visual trials using both a linear and quadratic model, we explored how the "difficulty" of the stimuli correlated with cortical activation. We found no group level effect of a quadratic model (suggesting that very little or none of the activation can be explained by a quadratic function of visual frequency of the checkerboard at 2,4 or $8 \mathrm{~Hz}$ or the wordsper-minute presentation of auditory stimuli) in either young or elderly groups.

A simpler linear model also had no explanatory power with respect to visual or auditory stimuli in the elderly group (i.e. no clusters survived even at lenient cluster thresholds). However, in the young group, there was a linear effect of auditory frequency in BA area 21 (left) suggesting that some variation in the group data could be explained as a linear function of word presentation frequency.

\section{Discussion}

We conclude that there may be compensatory mechanisms acting in the elderly participants in a non-specific (e.g. not necessarily related to stimulus difficulty) for auditory stimuli that are not present in the younger group. Similarly, in the visual conditions, we found bilateral visual cortical activity, and some activity in the left frontal gyrus suggesting a compensatory role for perhaps disambiguating complex visual stimuli. 
We also conclude that our parametric modulation approach did not possess significant statistical power to establish a relationship between parametric visual and auditory stimuli presentation frequency and cortical activation as evidenced by BOLD responses. Future work will explore more refined methods of exploring this relationship, and the relationship in young and elderly groups.

\section{References}

I. Rees G, Howseman A, Josephs O, Frith CD, Friston KJ, Frackowiak RS, Turner R: Characterizing the relationship between BOLD contrast and regional cerebral blood flow measurements by varying the stimulus presentation rate. Neuroimage 1997, 6:270-278.

2. Binder JR, Rao SM, Hammeke TA, Frost JA, Bandettini PA, Hyde JS: Effects of stimulus rate on signal response during functional magnetic resonance imaging of auditory cortex. Brain Res Cogn Brain Res 1994, 2:31-38.

Publish with Bio Med Central and every scientist can read your work free of charge

"BioMed Central will be the most significant development for disseminating the results of biomedical research in our lifetime. "

Sir Paul Nurse, Cancer Research UK

Your research papers will be:

- available free of charge to the entire biomedical community

- peer reviewed and published immediately upon acceptance

- cited in PubMed and archived on PubMed Central

- yours - you keep the copyright

Submit your manuscript here:

http://www.biomedcentral.com/info/publishing_adv.asp 